\title{
Reading Posthuman Ethics in Daniel Wilson's Amped
}

\author{
Omar M. Abdullah ${ }^{1}$, Hardev Kaur ${ }^{2}$ \\ ${ }^{1}$ Department of English, College of Education for Women, University of Anbar, Iraq \\ ${ }^{2}$ Department of English, Faculty of Modern languages and Communication, Universiti Putra Malaysia, Malaysia
}

\begin{abstract}
In $20^{\text {th }}$ century and beyond, humans have witnessed numerous advances in technology which have opened new horizons. Science and technology redesigned human life exponentially and humans always search for a more technological world and hence more comfort and ease. As such, going past human confinement could be accessible through a few changes in human form, but these changes posture a contentious point since people grow into being more reliant on technology in order to execute their desires and needs. What will happen to humanness and humanity? What will happen to their moralities and behaviors? In this manner, technological development could have both promising and discouraging pictures within the human mind. The current study cites Daniel H. Wilson's Amped (2013) to discuss the clash of views between Transhumanists and Bioconservatives. Transhumanists believe that human improvement advances should be made broadly accessible, where people could adopt these innovations and apply them to themselves to have a better life. In particular, bioconservatives consider human enhancement technologies as 'dehumanizing' for these technologies might weaken human dignity and affect something that is profoundly valuable about being human. As such, Posthuman theory is consulted in order to analyze the ethical and moral concerns of human enhancement technology in Wilson's Amped. The findings are summed in the importance of ethics in any kind of enhancement and conclude that the trustworthy source is a priority to ensure success.
\end{abstract}

KEY WORDS: Amped, Daniel Wilson, Ethics, Human Dignity, Posthuman, Technology

\section{INTRODUCTION:}

Technology has indeed become central in our everyday lives to the extent that human beings feel incomplete without it. Technology has now leaped to the point where scientists have managed to advance the human race. According to Bostrom and Roache (2008), human enhancement technologies essentially aim "to improve the state of an organism beyond its normal and healthy state" (1). Thus, it can be ascertained that human enhancement is built and designed to serve individuals who wish to improve themselves.

Koya University Journal of Humanities and Social Sciences (KUJHSS), Volume 4, Issue 1, 2021.

Received 11 May 2020; Accepted 23 Jun 2020,

Regular research paper: Published 30 Jun 2021

Corresponding author's e-mail: omar85x@ gmail.com

Copyright (C2021. Omar M. Abdullah, Hardev Kaur, this is an open access article distributed under the Creative Commons Attribution License.
It is undeniable that the prospects offered by the transhumanists (the advocates of human enhancement) are indeed very tempting; human enhancement technologies have the potential to achieve the impossible and unimaginable, for instance, the use of technology in eradicating diseases, improving human health and longevity. However, several concerns regarding the promising prospects of human enhancement technologies need to be raised. Bioconservatives (those who are strongly suspicious and critical of human enhancement technologies) question the ethics of 'messing with nature, tampering with our human essence, or displaying punishable hubris' (Bostrum 4). Bioconservatist Leon Kass who opposes the transhuman movement asks:

Why, if at all, are we bothered by the voluntary self-administration of agents that would change our bodies or alter our minds? What is disquieting about our attempts to improve upon human nature, or even our own particular instance of it? It is difficult to put this disquiet into words. We are in an area where initial repugnances are hard 
to translate into sound moral arguments. (Kass 2003,17)

This is therefore a pertinent yardstick in determining whether human enhancement technologies yield positive outcomes or not. In literature, the clash of views between transhumanists and bioconservatives is portrayed in Daniel H. Wilson's novel entitled Amped. Thus, the scope of this paper focuses on posthuman theory which will be used to analyse the ethical and moral concerns of human enhancement technology in Amped. More specifically, the study addresses issues of ethics in human enhancement technologies in relation to the posthuman.

\section{A GLANCE AT POSTHUMANISM}

Posthumanism and Transhumanism are two recent terms which carry in-depth meaning about human beings living in an advanced technological world. The relation between these two concepts, transhuman is concerned with the modified form of human by which new human remains biological, but enhanced and mostly concentrates on changing the capabilities of current human to heal diseases and stop death. Whereas, posthuman is defined as when a new being is less or non - biological form which is totally enhanced and mixed with advanced technology, but cannot be considered human anymore. Posthuman specifically centers on going far beyond transhuman and step into a nonhuman status in which the biology is outdated. Both terms in essence refer to "worldviews or philosophies" that highly favor a positive reply to the question of expanding human capabilities beyond limitations and "look forward to the day when homo sapiens have been replaced by biologically and technologically superior beings" (Hook, 2004, 2517). According to its advocates, transhumanism is the "intellectual and cultural movement that affirms the possibility and desirability of fundamentally improving the human condition through applied reason, especially by developing and making widely available technologies to eliminate aging and to greatly enhance human intellectual, physical and psychological capacities" (Bostrom, 2003,4).

Agar (2007) stated that the transhumanists basically look forward to a generation of posthumans whose qualities would exceed those of normal human beings. They would be much more resistant to disease and aging, whilst having unlimited youth and genius capabilities beyond imaginable limitations (12). In order to achieve these ends, the transhumanists resort to "genetic manipulations, nanotechnology, cybernetics, pharmacological enhancement and computer simulation" and the most controversial vision of the transhumanists yet: to create a generation of posthumans, through the "concept of mind uploading" (Hook, 2004, 2517).
The advancement of technologies will spawn a generation of posthumans "whose basic capacities so radically exceed those of present humans as to be no longer unambiguously human by our current standards" (Bostrom, 2003, 5). He further stated that the minds of the posthumans "may not be only more powerful than ours but may also employ different cognitive architectures or include new sensory modalities that enable greater participation in their virtual reality settings" (6). These advanced qualities may even enable posthumans to communicate using only their minds (6). Wilson and Haslam (2009) argued that the advancement in biosciences has led to the existence of technologies such as NBIC (nanotechnology, biotechnology, information technology, and cognitive science) and GRAIN (genetic manipulation, robotics, artificial intelligence, and nanotechnology). Furthermore, Kurzweil (1999) and Seiler (2007) claimed that these technologies are designed specifically for the "creation of new living organisms, machines with human or superhuman intelligence, and humans with machine parts and genetically enhanced bodies" (qtd in Wilson and Haslam, 2009, 249).

Wilson and Haslam (2009) further stated that "there is a profound disagreement between advocates and opponents as to whether the application of such technologies to humankind will be humanizing, superhumanizing, or dehumanizing" (249).

According to Bostrom and Roache (2008), human enhancement acts "to improve the state of an organism beyond its normal healthy state" (1). Among the important theorists who advocate enhancement are Nick Bostrom, Julian Savulescu, James Hughes, Gregory Stock, Nick Agar, Rodney Brooks, Hans Moravec, Ray Kurzweil, and Lee Silver (Wilson and Haslam, 2009, 249250). They contend that human enhancement means that humans will be able to enhance their uniqueness and thus move away from their animality (Wilson and Haslam, 2009, 259).

On the other hand, bioconservatives comprising thinkers such as Leon Kass, Francis Fukuyama, Jeremy Rifkin, Bill McKibben, Jurgen Habermas, Michael Sandel, and Margaret Somerville, believe that human enhancement technologies undermine human dignity. They believe that modifying humankind through the use of technologies goes against the grain of human nature, and will thereby produce "dehumanized" beings (Wilson and Haslam, 2009, 256).

Thus, using human enhancement technologies requires further attention. One of the fundamental issues raised is whether "human beings should augment or enhance themselves and future generations?" (Hook, 2004, 2518). This question has led to much debate between the transhumanists and the bioconservatives. 


\section{ETHICS IN POSTHUMAN}

Transhumanists "believe that science and technology can and should be used to overcome all human limitation" (Lake, 2014, 2). They believe that biotechnology is the way forward towards attaining artificial intelligence, phenomenal memory, altered and improved mental, emotional and physical health.

On the other hand, humanists who oppose human enhancement would not "willingly consent to transforming humankind to the extent that it ceases to be human" (Waters, 2016, 74-5). If human enhancement terminates the very existence of human, its notion can destroy the measure and goal of moral Enterprise. Humanists believe in human modification for corrective, reparative and therapeutic purposes nevertheless, even bioethicists are unable to discern the fine line between therapeutic modification and enhancement. Just as eyeglasses are used to correct and improve vision and astigmatism, Koch explains that "they are simply technologies serving a limited corrective function" (687). This type of therapeutic modification is not permanent; it only serves to repair the problem without changing the concept of humanity.

The ethical viewpoint of human enhancement forces one to look beyond science and technology to determine its advantages to mankind. It would seem that moral progress, as the benchmark for ethics, has failed to keep up with science and technology. Waters in his book stated that "it was crucial that the distance be narrowed, and narrowed quickly, in order that scientific knowledge could be applied in a more humane manner" (13). Hence, ethics in human enhancement is achieved only when its technology is used for therapeutic, corrective and reparative purposes without sacrificing humanity.

Michael J. Sandel as one of the prominent bioconservatives demands that human enhancement ought to be avoided because it communicates an intemperate want to alter oneself and become aces of our nature (Douglas, 2008). For instance, within the field of cognitive improvement, he contends that ethical issue we ought to be concerned with is the outcomes of inequality of access to such technology in conceivably making two classes of humans. So also, he has argued that the ethical issue with genetic engineering is not that it undermines the child's independence, as this claim wrongly implies that absent a designing parent, children are free to choose their features for themselves" (Sandel, 2007). Rather, he sees upgrade as hubristic, taking nature into our own hands: seeking after the fixity of upgrade is an instance of vanity (Savulescu \& Kahane, 2009). In brief Sandel contends that the genuine moral issues with genetic engineering concern its impacts on humility, responsibility and solidarity (Sandel, 2007).
Therefore, Sandel contends that humility is an ethical virtue that will be impaired by genetic engineering. He assures that humility empowers one to abide the unexpected, to live with dissonance, to rein in the impulse control (2007) and thus, is worth cultivating in all perspectives of one's life. He adds there will be an 'explosion' of obligation on humankind due to the expanding part of genetic enhancement. He argues that genetic engineering will increase parental duty as parents become responsible for choosing, or failing to select, the proper characteristics for their children. He agrees that such obligation will lead to genes becoming a matter of choice rather than a matter of chance. Solidarity also plays a role in its impact on the moral issues of genetic enhancement. Sandel explains that without genetic engineering, a child is at the mercy of the genetic lottery. Insurance markets permit a pooling of risk for the benefit of all: those who become healthy subsidies while others do not. This means that individual success is not fully determined by that individual or their parents, as genetic traits are to some extent randomly assigned from a collective pool.

This study investigates why the programme of human enhancement in Amped is unethical; how it has created dissension between the "pure" humans and the "amps" and why ethics is crucial in governing the future of posthumans. This analysis will be divided into three main levels, namely individual, professional and societal.

\section{INDIVIDUAL LEVEL}

On the individual level, the absence of good ethics in human enhancement technology, can demoralize people. Amped starts off with the suicide of Samantha who was 15 years old. She kills herself because she is considered 'different' from the other normal children. Her parents had decided to implant the Neural Autofocus in her brain to enhance her powers of concentration. This consequently led to her being barred from school because she was now an 'amp'. With mounting pressure from the Pure Human Citizen's Council, Samantha realizes that being an amp will not secure her a good future. This is evident when she says "Sam's gone. I'm somebody else. Somebody that never should have existed" (Wilson, 2013, 13). Owen, the main protagonist, feels that the brain implant has actually turned Samantha into someone else when he says, "It was too much, the gap between the old Samantha and the new. Something broke in that week she was gone. A piece of her must have got lost in the transition" (Wilson, 2013,11).

Despite doing what her parents' thought was best for her, Samantha could not cope with the stigma of being an enhanced human being and thus ends her life. After Samantha's death, we realize that Owen is also an amp, 
an advanced amp equipped with a military type of device. Owen, we are told, is a good man, kindhearted and humble and these attributes will compel him to do good deeds once the device is turned on. However, it would have negative consequences in a bad person implanted with this device. This is evident in the following conversation between Jim and Owen, "All I do know is that when you turn it on, the amp takes over. You go faster. No time to think. If you're a good man, you'll do good things. If you're not, you won't" (Wilson, 2013,73).

Owen Gray, 29 years old, was an ordinary high school teacher before he became an amp. Owen's father who is a surgeon has implanted a device in his son's brain in order to control his epilepsy. When it dawns on him that he is an enhanced human, Owen feels betrayed. He says to his father, "You didn't give me a life...You stole it" (Wilson, 2013, 30). Owen's father, like Samantha's parents, only wants the best for his son and explains to Owen, "You've got to realize, Owen, that without the amp you would have died. It is a part of you, but you have to give it permission. I gave you something extra" (Wilson, 2013, 30). This 'extra' means that the implant can also function as a sophisticated weapon. To his father, that "something extra" is for Owen "to do good" and he says to Owen, "when the time comes, you have to activate the amp willingly" (Wilson, 2013,30).

The implant has the potential to wreak havoc when its recipient becomes angry or violent. According to Miah (2011), "an individual's ethical issues relates directly to the interest of the subject who is undertaking the enhancement themselves" (11). Owen, however, is a good person who does not misuse his device but endeavors to find out more about it. He then escapes to Eden, a trailer camp in Oklahoma that serves as a refuge for amps, to find a man named Jim Howard who can fulfill his quest.

Jim exemplifies the importance of ethics in governing the future of posthumans. He is a Biomedical engineer but he quits his job and starts "working construction" (Wilson, 2013, 62). He justifies his actions by saying "once, I designed neural implants for a living. Government $\mathrm{R}$ and D. Basic architecture stuff. I quit when I lost sight of whether the Autofocus was a good thing or an evil thing. Still couldn't tell you. So, I guess I'll be out here breaking rocks until I figure it out" (Wilson, 2013, 62). This proves that an individual with good ethics can differentiate between moral and immoral.

\section{PROFESSIONAL LEVEL}

The professional level involves the production of technology. Therefore, ethics is crucial to ensure good production and facilitation of human enhancement technologies. Through Jim Howard we learn that the
American government has set up an illegal operation about Zenith, the implant in Owen's brain:

What the hell is in my head, Jim?" I ask. Jim squints at me in the glare of the sun. "It's called the Zenith-class amp. A prototype. There were twelve of them officially installed. A team of handpicked soldiers. Later, when the press found out, they were called Echo Squad. Turns out, the whole operation was illegal. Squad went away and those disgraced soldiers spread to the wind. All that was in the news. (Wilson, 2013,62)

Jim is worried about the illegality and misuse of such technology on humans. Jim further reveals that he had made the thirteenth instalment of Zenith in secret which has now been implanted inside Owen's brain:

What never saw print was this: a thirteenth Zenith was made in secret. I made it myself and I copied the encrypted military stuff onto it so it would work. Dropped it into an envelope and mailed it to your old man. He made you the thirteenth. Saved your life, but, like everything, it came with a price. You've got a weapon inside you, Owen. A weapon that's never been turned on. With your pop's office raided, I imagine the government knows all about it by now. (Wilson, 2013,62)

Obviously, what Jim did was unethical. As a professional, he should have exercised discretion with good judgment and ethics.

We also learn from this science fiction novel that the American government has authorized a programme called the Uplift Program which aims "to provide technological benefits to disadvantaged students and to strengthen education" (63). This programme aims "to improve the educational performance of low-income children by enhancing their cognitive, physical, and emotional development" by providing them the "access to implantable medical technology, such as Neural Autofocus" (63). While the government's intentions are noble, they fail to realize that this programme actually yields a negative outcome. The novel further describes the way in which the government deals with a group of Zenith-amps who are beyond control, by killing them. Yet again, the government has acted negligently, unethically and unprofessionally: here, the Zenith-amp soldiers have become collateral damage.

\section{SOCIETY LEVEL}

On the societal level, good ethics will ensure nonfragmentation of society. In the novel, there are elements of discrimination on both individual and institutional levels, segregation, prejudice and structural violence. All of these factors contribute to a fragmented society.

After the United States Supreme Court rules against the amps, discrimination against them becomes legal (Wilson, 2013, 6). Consequently, a ferocious culture war 
between the "pure" humans and the implanted humans begins to turn violent. Millions of citizens with brain implants are fired from their jobs, evicted from their homes and attacked in the streets. They flee for their lives and band together in camps and rural areas. Wilson shows that the "pure" humans are worried because of the growing number of amps:

The Pure Human Citizen's Council is reveling in the decision. The organization grew up organically in the last decade, responding to amps like a foreign body rejection. At first the PHCC was a religious nonprofit. Sanctity of the body, love what God gave ya - that sort of thing. But then they got support from all over and they got it fast. Middle-class families who worried their kids wouldn't be able to compete in the new future. Labor unions with an eye on keeping jobs for their human members. And politicians who knew a good bandwagon when they saw it. (Wilson, 2013, 16)

Those who do not advocate human enhancement technologies are afraid of the foreseeable future with amps. The amps had begun to regard themselves as superior to normal humans. This is evident when Lyle tells Owen that he wants to incur a "change" from the war between the "pure" humans and the:

Then you know the order, says Lyle. Plants, animals, men, angels, then God. Difference between men and angels is that men are stuck in a body. They feel pain, hunger, thirst. But me and you, we don't have to feel them things. Body diagnostics comes on level one. Easy. We can turn off the human condition. So maybe we're closer to angels, you know? Creatures of the mind. A higher morality. amps (Wilson, 2013, 164)

His language reflects his air of superiority. The device does not transform individuals into something new; its function is to remedy their deficiencies and amplify their abilities. This disparity becomes a divisive element in a society where normal humans and enhanced human cease to co-exist. As for the normal humans, they are just afraid of the unknown and refuse to live harmoniously with the amps. Thus, it is crucial that ethics, like good governance, should unite both parties instead of pulling them asunder.

\section{CONCLUSIONS}

It is fine for individuals to opt for human enhancement technologies for their own benefit but ethics is crucial to ensure a positive outcome for the common good of all. If the enhancement is gained from an authorized and trusted source, and is used for all the right reasons, then it is ethical. The professionals who are responsible for the production and facilitation of such technologies must ensure they are bona fide and beneficial to mankind. At the social level, accessibility to and affordability of these technologies must be wisely administered; failure to do this may result in dire consequences and disunity. Specific bio enhancements should be opposed when they may cause harm to us, outweigh the benefits that the presentation of such enhancements can sensibly be anticipated to supply such as the case of Samantha and Owen who suffered from the impacts of the implantation process. Samantha could not handle this implant since it shows her as a pariah within the society as the process is not presented in a correct suitable manner. Concurrently, bio enhancement could also be beneficial to education if there are techniques that enable individuals to become more receptive to education, or enhance their capacity to make the foremost of their education, ethics and over all avoidance from status quo bias.

\section{REFERENCES}

Agar, N. (2007). Where to Transhumanism? The Literature Rea ches a Critical Mass. The Hastings Center Report, 37(3), 12-17.

Bostrom, N., Roache, R., Petersen, T. S., Ryberg, J., \& Wolf, C. (2008). New waves in applied ethics. Basingstoke, Hampshire, [etc.: Palgrave Macmillan.

Bostrum, N. (2007). Human vs. posthuman. The Hastings Center Report, 37(5), 4 .

Douglas, T. (2008), Moral Enhancement. Journal of Applied Philosophy, 25: 228-245. https://doi.org/10.1111/j.14685930.2008.00412.x

Hook, C. C. (2004). Transhumanism and posthumanism. Encyclopedia of bioethics.

Kass, L. R. (2003). Ageless bodies, happy souls: biotechnology and the pursuit of perfection. The New Atlantis, (1), 9-28.

Koch, T. (2010). Enhancing who? Enhancing what? Ethics, bioethics, and transhumanism. Journal of medicine and Philosophy, 35(6), 685-699

Kurzweil, R. (1999). The age of spiritual machines: how we will live, work and think in the new age of intelligent machines. Orion.

Lake, C. B. (2014). Prophets of the posthuman: American fiction, biotechnology, and the ethics of personhood. University of Notre Dame Press.

Sandel, M. J. (2007). The case against perfection. Harva rd u niversity press.

Savulescu, J., \& Kahane, G. (2009). The moral obligation to create children with the best chance of the best life. Bioethics, 23(5), 274290. https://doi.org/10.1111/j.1467-8519.2008.00687.x

Waters, B. (2016). From human to posthuman: Christian theology and technology in a postmodern world. Routledge.

Wilson, D. H. (2013). Amped. Vintage.

Wilson, S., \& Haslam, N. (2009). Is the future more or less human? Differing views of humanness in the posthumanism debate. Journal for the Theory of Social Behaviour, 39(2), 247-266.

Bostrom, N. (January 01, 2003). When machines outsmart humans. Futures Guildford-, 35, 7, 759-764. 